\title{
Direct Silyl Ether Metathesis for Vitrimers with Exceptional Thermal Stability \\ Supporting Information
}

\author{
Chase A. Tretbar, James A. Neal, Zhibin Guan* \\ Department of Chemistry, University of California, Irvine, California 92697, United States
}

\section{Table of Contents}

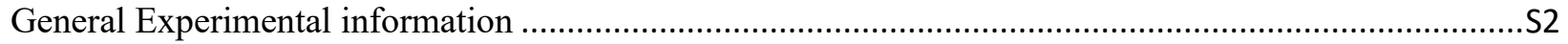

Small molecule model studies for silyl ether metathesis .....................................................................S3

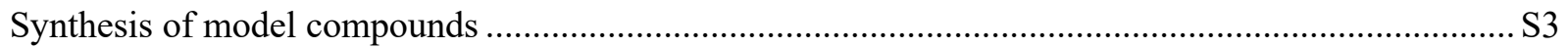

NMR Spectra of small molecule model compounds …...................................................................... S4

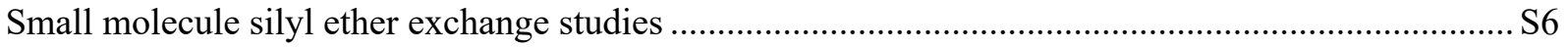

Representative GC-MS chromatograms for model reaction studies ................................................ S6

Synthesis of silyl ether functionalized polymer and cross-linker .......................................................S8

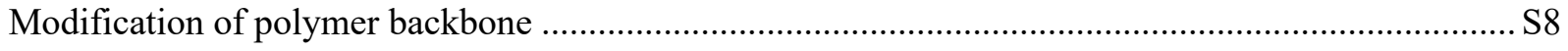

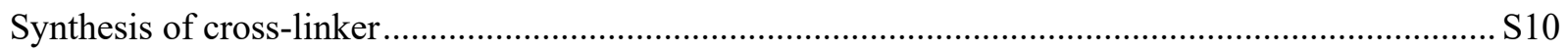

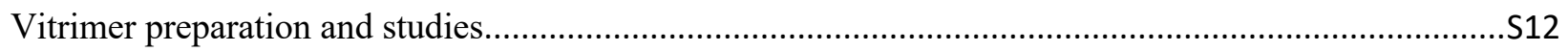

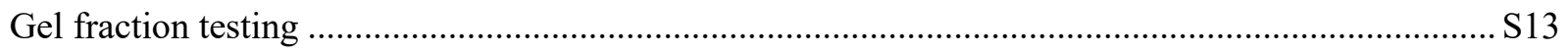

Thermal characterization of PE-OTMS vitrimer...................................................................... S14

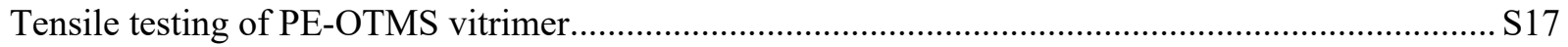

Dynamic Mechanical Thermal Analysis (DMTA) testing ……........................................................ S19

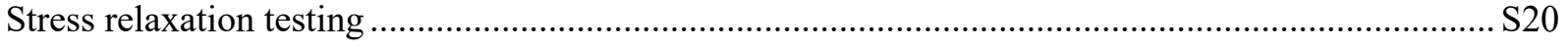

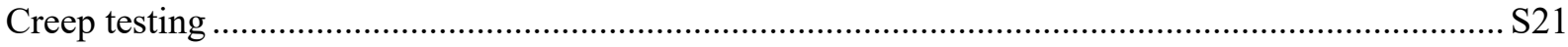

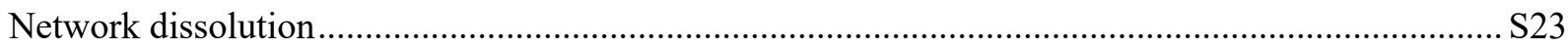

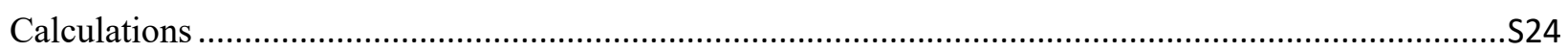

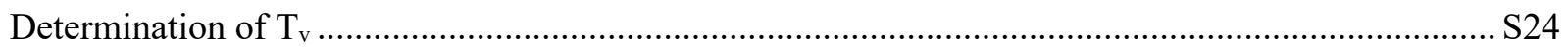

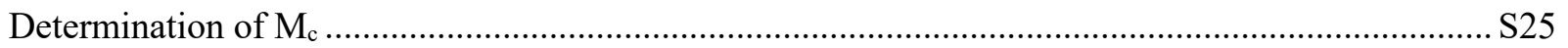

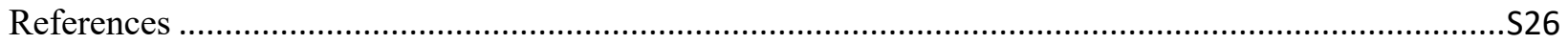




\section{General Experimental information}

Unless otherwise noted, reactions were carried out with dry solvents using a magnetic stir bar. Commercial reagents were used as received with no further purification, unless otherwise noted. ${ }^{1} \mathrm{H}$ NMR spectra were recorded at either $500 \mathrm{MHz}$ on a Bruker DRX500 spectrometer or at $600 \mathrm{MHz}$ on a Bruker AVANCE600 spectrometer. ${ }^{13} \mathrm{C}$ NMR spectra were recorded at $125.2 \mathrm{MHz}$ using a Bruker AVANCE600 with a BBFO cryoprobe. NMR spectra peaks are reported as $\delta$ values in ppm relative to TMS or residual solvent: $\mathrm{CDCl}_{3}\left({ }^{1} \mathrm{H}=7.26 \mathrm{ppm} ;{ }^{13} \mathrm{C}=77.0 \mathrm{ppm}\right), \mathrm{C}_{6} \mathrm{D}_{6}\left({ }^{1} \mathrm{H}=\right.$ $\left.7.16 \mathrm{ppm},{ }^{13} \mathrm{C}=128.06 \mathrm{ppm}\right) .{ }^{1} \mathrm{H}$ NMR data are reported as follows: chemical shift in ppm, multiplicity ( $\mathrm{s}=$ singlet, $\mathrm{d}=$ doublet, $\mathrm{t}=$ triplet), coupling constants in $\mathrm{Hz}$, and relative integration of the number of protons. Multiplets (m) are reported over the range of chemical shift at which they appear. For ${ }^{13} \mathrm{C}$ NMR, only chemical shift values are reported. Tensile tests were performed on an Instron 3365 mechanical tester. Differential Scanning Calorimetry (DSC) thermograms were evaluated using a TA Instruments Q2500. Thermogravimetric Analysis (TGA) thermograms were evaluated using a TA Instruments Q500. Dynamic Mechanical Thermal Analysis (DMTA) analysis was evaluated using a TA Instruments Q800. Gas chromatography-mass spectrometry experiments (GC-MS) were taken using a Thermo Scientific ISQ GC Ultra. 


\section{Small molecule model studies for silyl ether metathesis}

\section{Synthesis of model compounds}

Scheme S1. Synthesis of ethyltributoxysilane and ethyltripentoxysilane.

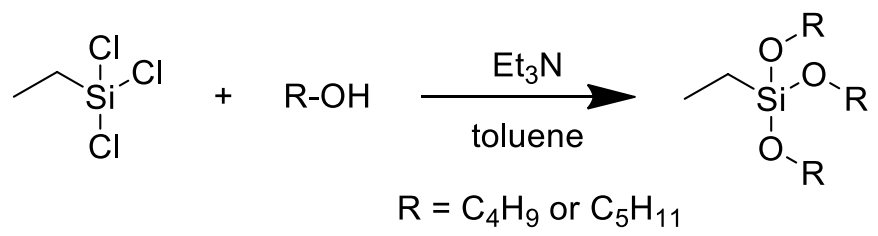

Representative synthesis of alkoxy silanes: To a flame-dried $\mathrm{N}_{2}$-purged round bottom flask equipped with an air condenser, toluene ( $30 \mathrm{~mL}$ ), triethylamine (5 equiv., $8.82 \mathrm{~g}, 13.77 \mathrm{~mL})$, and alcohol (5 equiv.) were added. The flask was cooled to $0{ }^{\circ} \mathrm{C}$ followed by the dropwise addition of trichloroethylsilane (1 equiv., $2.64 \mathrm{~mL}$ ). The vessel was brought to reflux at $115^{\circ} \mathrm{C}$ for 5 hours. After cooling to room temperature, the reaction mixture was filtered to remove TEA-HCl salts followed by the removal of excess alcohol by rotary evaporation. The crude mixture was purified by vacuum distillation to yield a clear liquid. The identity and purity of the product was confirmed by ${ }^{1} \mathrm{H}$ NMR and ${ }^{13} \mathrm{C}$ NMR.

$\mathrm{R}=\mathrm{C}_{4} \mathrm{H}_{9}: 3.53 \mathrm{~g}, 64 \%$ yield

$\mathrm{R}=\mathrm{C}_{5} \mathrm{H}_{11}: 3.26 \mathrm{~g}, 51 \%$ yield

EtSi(OBu) ${ }_{3}{ }^{1} \mathrm{H}$ NMR $\left(500 \mathrm{MHz}, \mathrm{CDCl}_{3}, 298 \mathrm{~K}\right) \delta 3.74$ (t, J=6.7, 6H), $1.56(\mathrm{~m}, 6 \mathrm{H}), 1.38$ (sxt, $\mathrm{J}=7.6,6 \mathrm{H}), 0.99(\mathrm{t}, \mathrm{J}=8.0,3 \mathrm{H}), 0.92(\mathrm{t}, \mathrm{J}=7.4,9 \mathrm{H}), 0.62(\mathrm{q}, \mathrm{J}=8.0,2 \mathrm{H}) .{ }^{13} \mathrm{C}$ NMR $(125 \mathrm{MHz}$ $\left.\mathrm{CDCl}_{3}, 298 \mathrm{~K}\right) \delta 62.60,34.83,19.07,14.00,6.69,2.32$.

EtSi(OPn) ${ }_{3}{ }^{1} \mathrm{H}$ NMR $\left(500 \mathrm{MHz}, \mathrm{CDCl}_{3}, 298 \mathrm{~K}\right) \delta 3.73(\mathrm{t}, \mathrm{J}=6.8,6 \mathrm{H}), 1.57(\mathrm{~m}, 6 \mathrm{H}), 1.33(\mathrm{~m}$, 12H), 0.99 (t, J=8.0, 3H), 0.90 (m, 9H), 0.62 (q, J=8.0, 2H). ${ }^{13} \mathrm{C}$ NMR (125 MHz, $\left.\mathrm{CDCl}_{3}, 298 \mathrm{~K}\right)$ $\delta 62.92,32.42,28.10,22.62,14.21,6.70,2.33$. 


\section{NMR Spectra of small molecule model compounds}

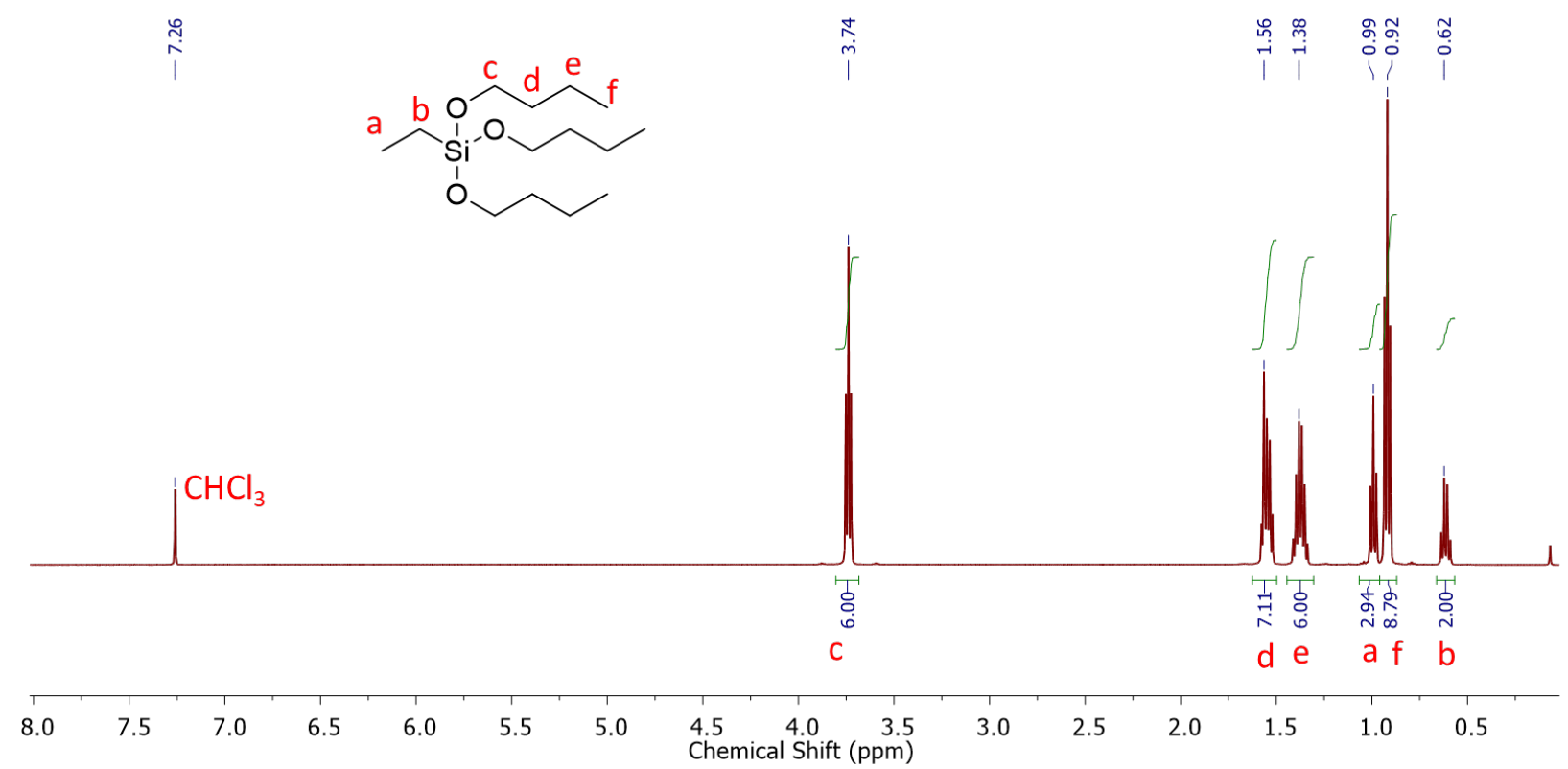

Figure S1. ${ }^{1} \mathrm{H}$ NMR $\left(500 \mathrm{MHz}, \mathrm{CDCl}_{3}, 298 \mathrm{~K}\right)$ spectrum for $\mathbf{E t S i}(\mathbf{O B u})_{3}$
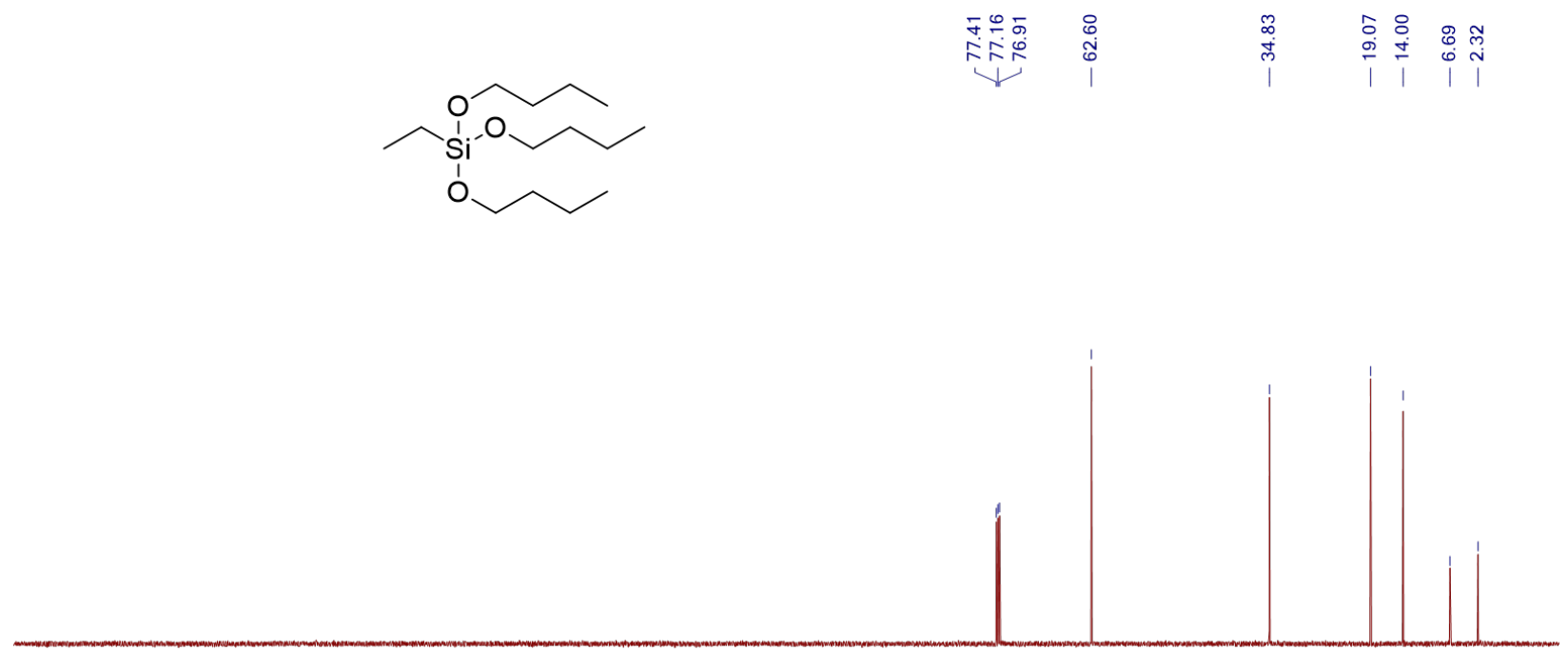

$\begin{array}{lllllllllllllllllllllllll}30 & 220 & 210 & 200 & 190 & 180 & 170 & 160 & 150 & 140 & 130 & 120 & 110 & 100 & 90 & 80 & 70 & 60 & 50 & 40 & 30 & 20 & 10 & 0 & -1\end{array}$

Figure S2. ${ }^{13} \mathrm{C}$ NMR $\left(125 \mathrm{MHz}, \mathrm{CDCl}_{3}, 298 \mathrm{~K}\right)$ spectrum for $\left.\mathbf{E t S i ( O B u}\right)_{3}$ 


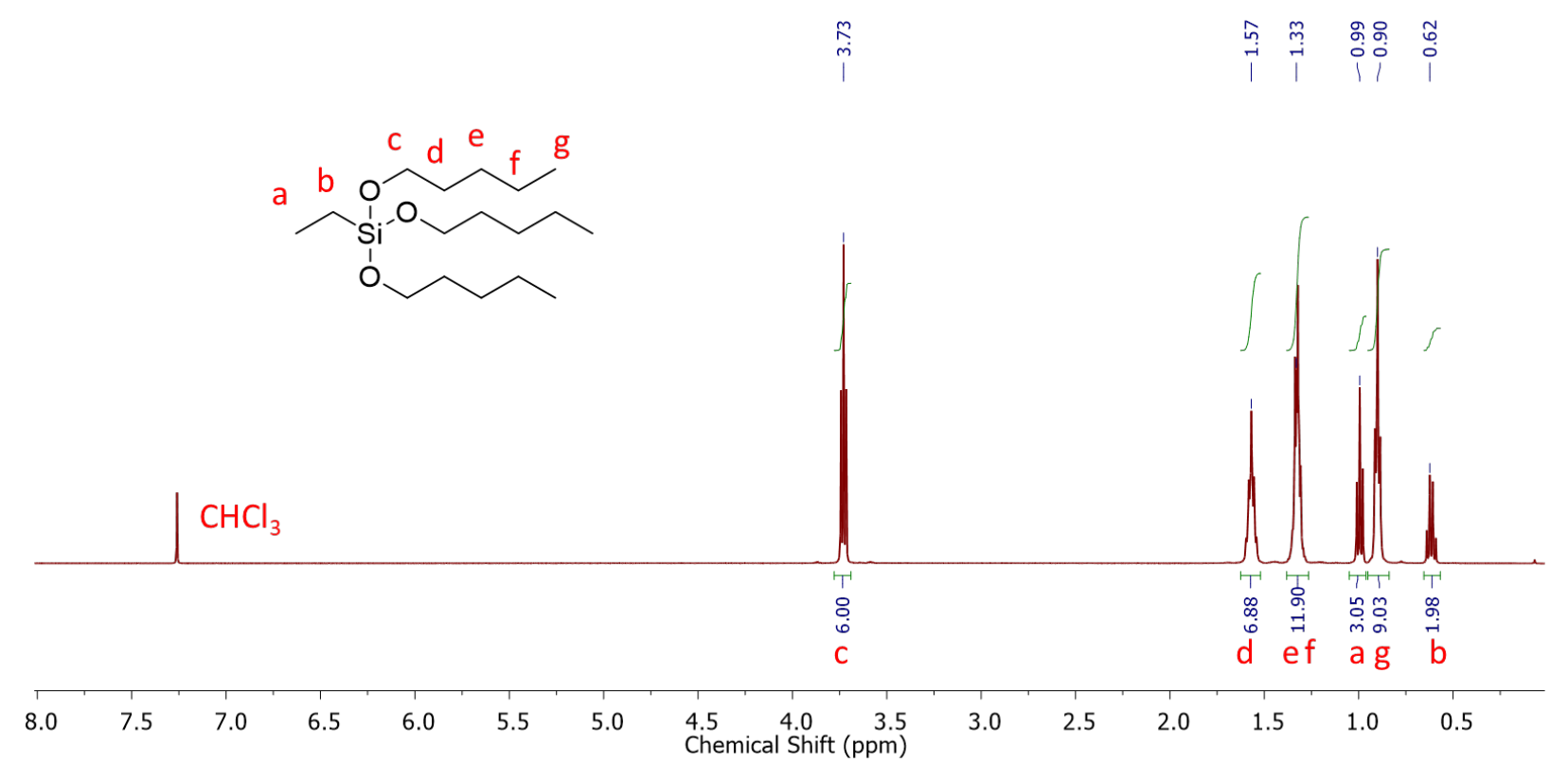

Figure S3. ${ }^{1} \mathrm{H}$ NMR $\left(500 \mathrm{MHz}, \mathrm{CDCl}_{3}, 298 \mathrm{~K}\right)$ spectrum for $\mathbf{E t S i ( O P n )} 3$

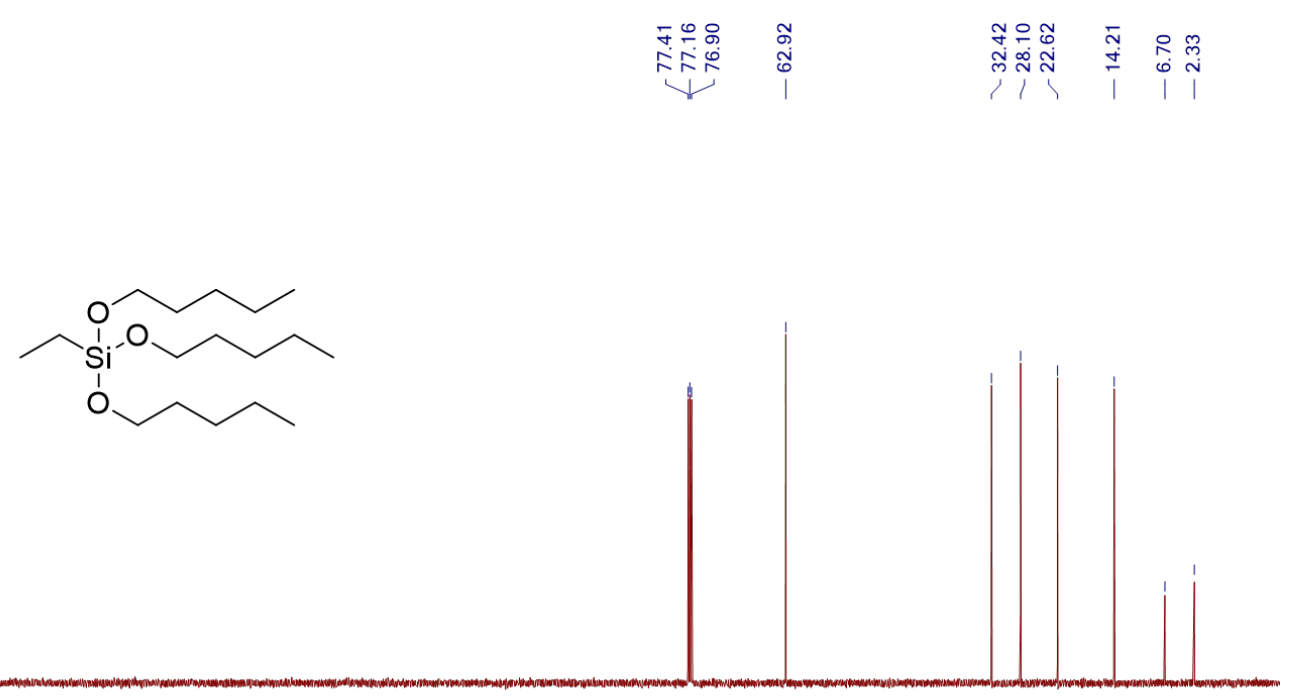

$\begin{array}{lllllllllllllllllllllllllllllllllllllll} & 30 & 220 & 210 & 200 & 190 & 180 & 170 & 160 & 150 & 140 & 130 & 120 & 110 & 100 & 90 & 80 & 70 & 60 & 50 & 40 & 30 & 20 & 10 & 0 & -1\end{array}$

Figure S4. ${ }^{13} \mathrm{C}$ NMR $\left(125 \mathrm{MHz}, \mathrm{CDCl}_{3}, 298 \mathrm{~K}\right)$ spectrum for EtSi(OPn)3 


\section{Small molecule silyl ether exchange studies}

Silyl ether metathesis model reactions were investigated under different temperatures with different acid catalysts. After a brief screen of multiple Lewis acid and Brønsted acid catalysts, the three most promising were found to be camphor sulfonic acid (CSA), $\mathrm{Zn}(\mathrm{OTf})_{2}$, and $\mathrm{Sc}(\mathrm{OTf})_{3}$. The model exchange reaction was performed as following: Dimethylacetamide $(0.33 \mathrm{~mL})$ and catalyst ( 0.1 equiv., $0.033 \mathrm{mmol}$ ) were added to a flame dried and $\mathrm{N}_{2}$-purged flask, followed by $\mathrm{EtSi}(\mathrm{OBu})_{3}(1$ equiv., $0.33 \mathrm{mmol}, 0.092 \mathrm{~g})$ and $\mathrm{EtSi}(\mathrm{OPn})_{3}(1$ equiv., $0.33 \mathrm{mmol}, 0.106 \mathrm{~g})$ via tared syringe. For the small molecule model exchange without catalyst, anhydrous trichlorobenzene was used instead of dimethylacetamide due to its higher boiling point. The flask was heated to the indicated reaction temperature. Aliquots were taken at different points and analyzed via gas chromatography mass spectrometry (GC-MS).

\section{Representative GC-MS chromatograms for model reaction studies}

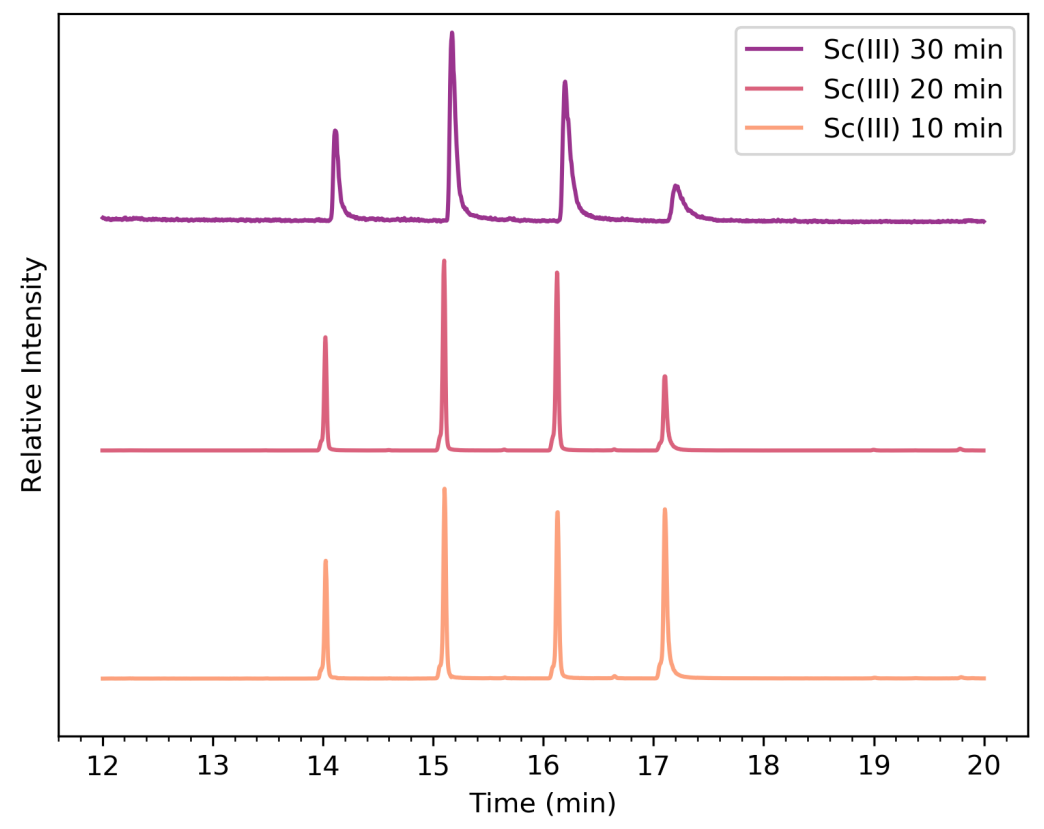

Figure S5. GC-MS chromatogram for $\mathrm{Sc}(\mathrm{OTf})_{3}$ catalyzed silyl ether exchange at $60{ }^{\circ} \mathrm{C}$. 


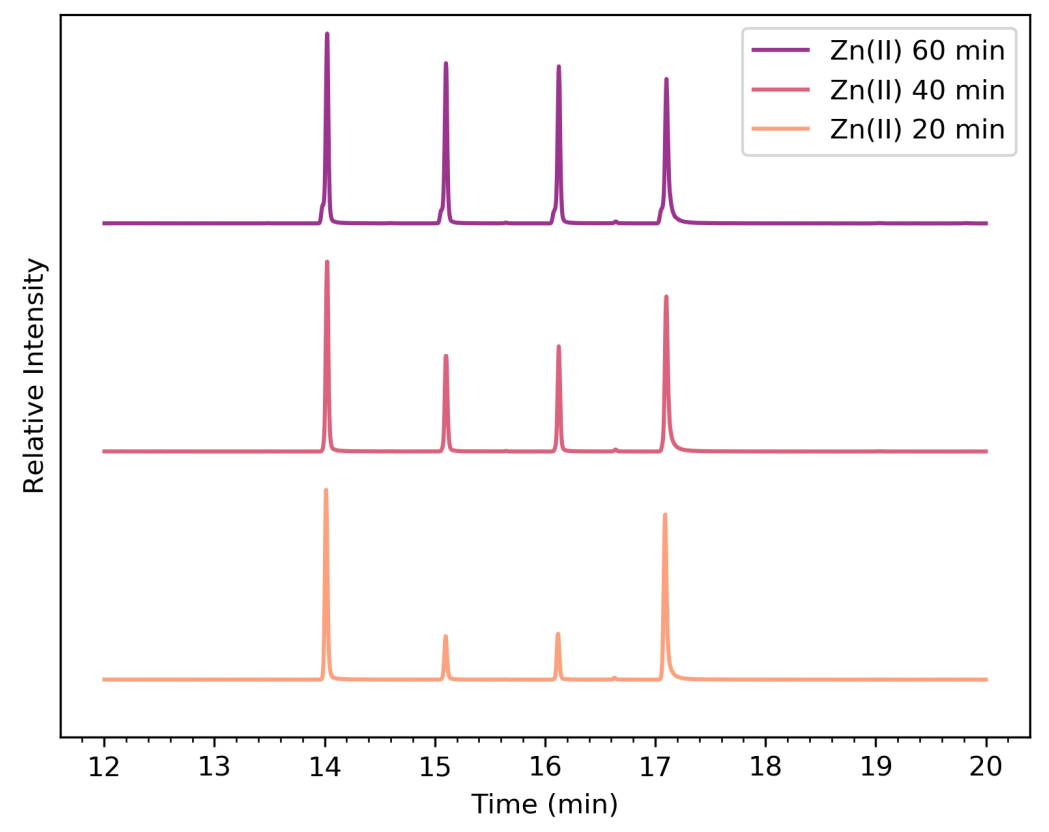

Figure S6. GC-MS chromatogram for $\mathrm{Zn}(\mathrm{OTf})_{2}$ catalyzed silyl ether exchange at $60{ }^{\circ} \mathrm{C}$.

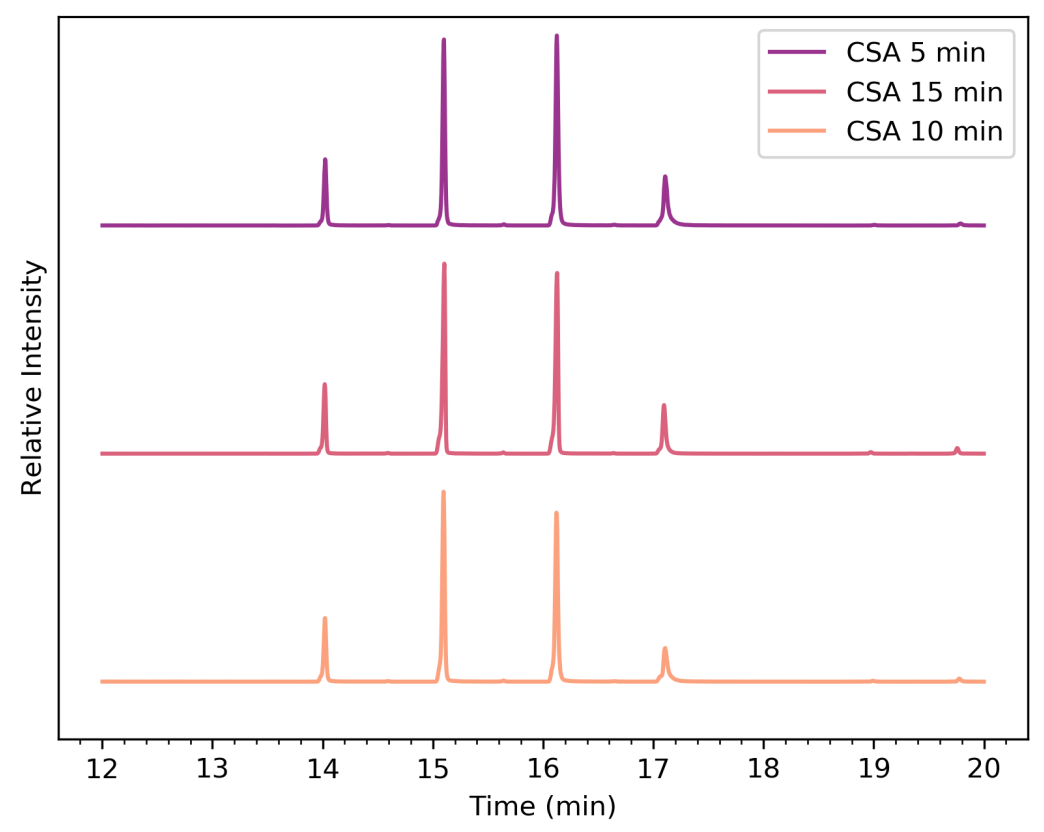

Figure S7. GC-MS chromatogram for CSA catalyzed silyl ether exchange at $60{ }^{\circ} \mathrm{C}$. 


\section{Synthesis of silyl ether functionalized polymer and cross-linker}

\section{Modification of polymer backbone}

Scheme S2. Hydrolysis of EVA.

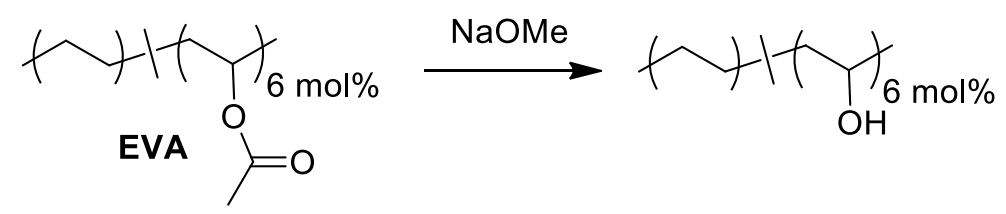

Poly(ethylene-co-vinyl acetate) (EVA) (50 g, Celanese 1850A, $18.2 \mathrm{wt} \%$ VA, MFI $=150 \mathrm{~g} / 10$ min) was dissolved in $1 \mathrm{~L}$ toluene and heated to $75^{\circ} \mathrm{C}$. To the stirred solution, $25 \mathrm{wt} . \%$ sodium methoxide in methanol (1.5 equiv., $34.3 \mathrm{~g}$ ) was added and the solution was stirred overnight. Finally, to the gently stirring solution $\mathrm{HCl}$ (1 equiv., $3 \mathrm{M}, 52.3 \mathrm{~mL}$ ) was added followed by stirring for 20 minutes. The aqueous layer was removed via cannulation and the organic phase was washed twice with hot brine to reduce the emulsion. The resulting organic phase was precipitated into vigorously stirred $\mathrm{MeOH}$, filtered and dried under vacuum overnight at $85{ }^{\circ} \mathrm{C}$ to yield poly(ethylene-co-vinyl alcohol) which was characterized by ${ }^{1} \mathrm{H}$ NMR spectroscopy.

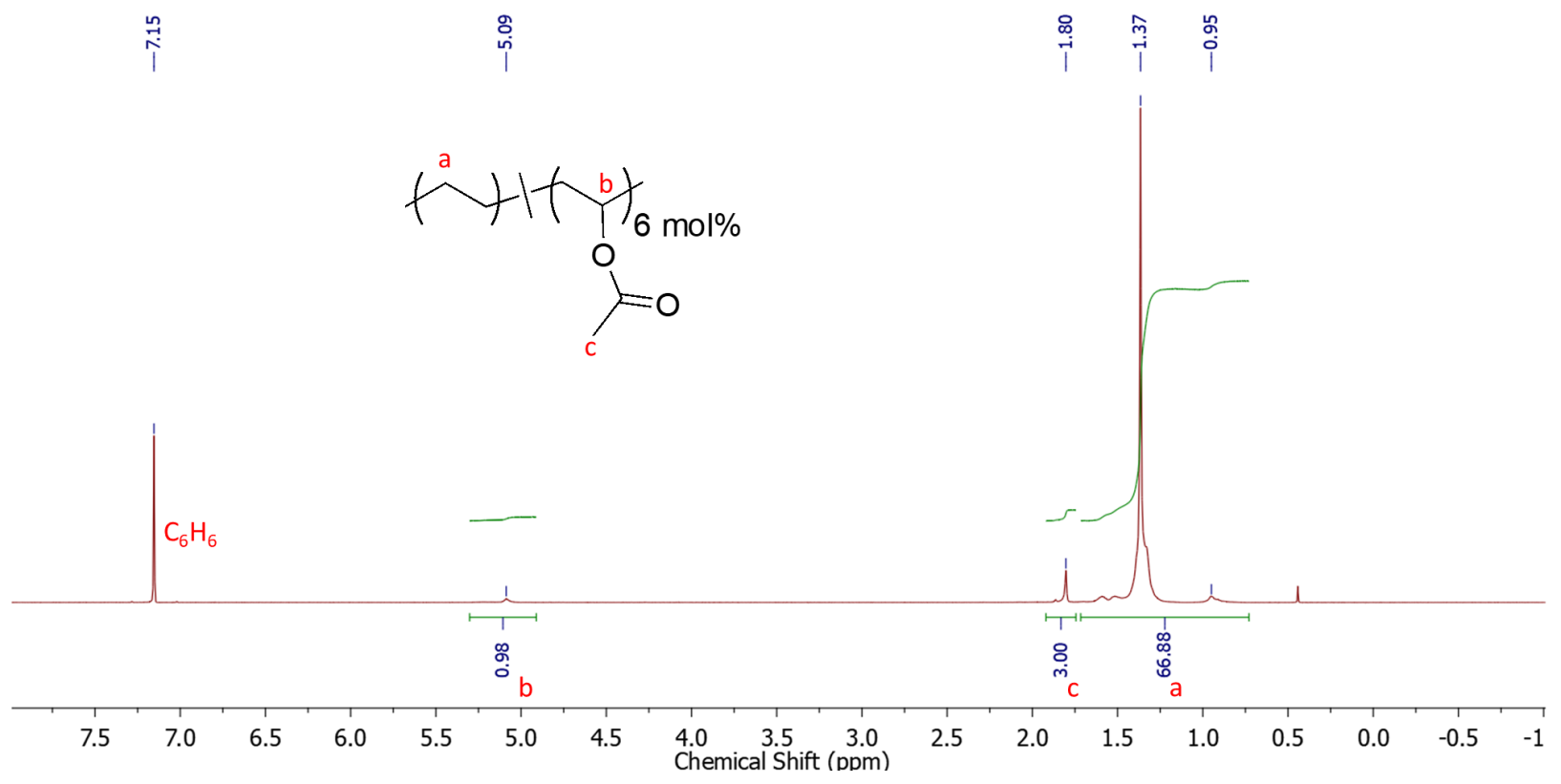

Figure S8. ${ }^{1} \mathrm{H}$ NMR $\left(600 \mathrm{MHz}, \mathrm{C}_{6} \mathrm{D}_{6}, 333 \mathrm{~K}\right)$ spectrum of EVA 


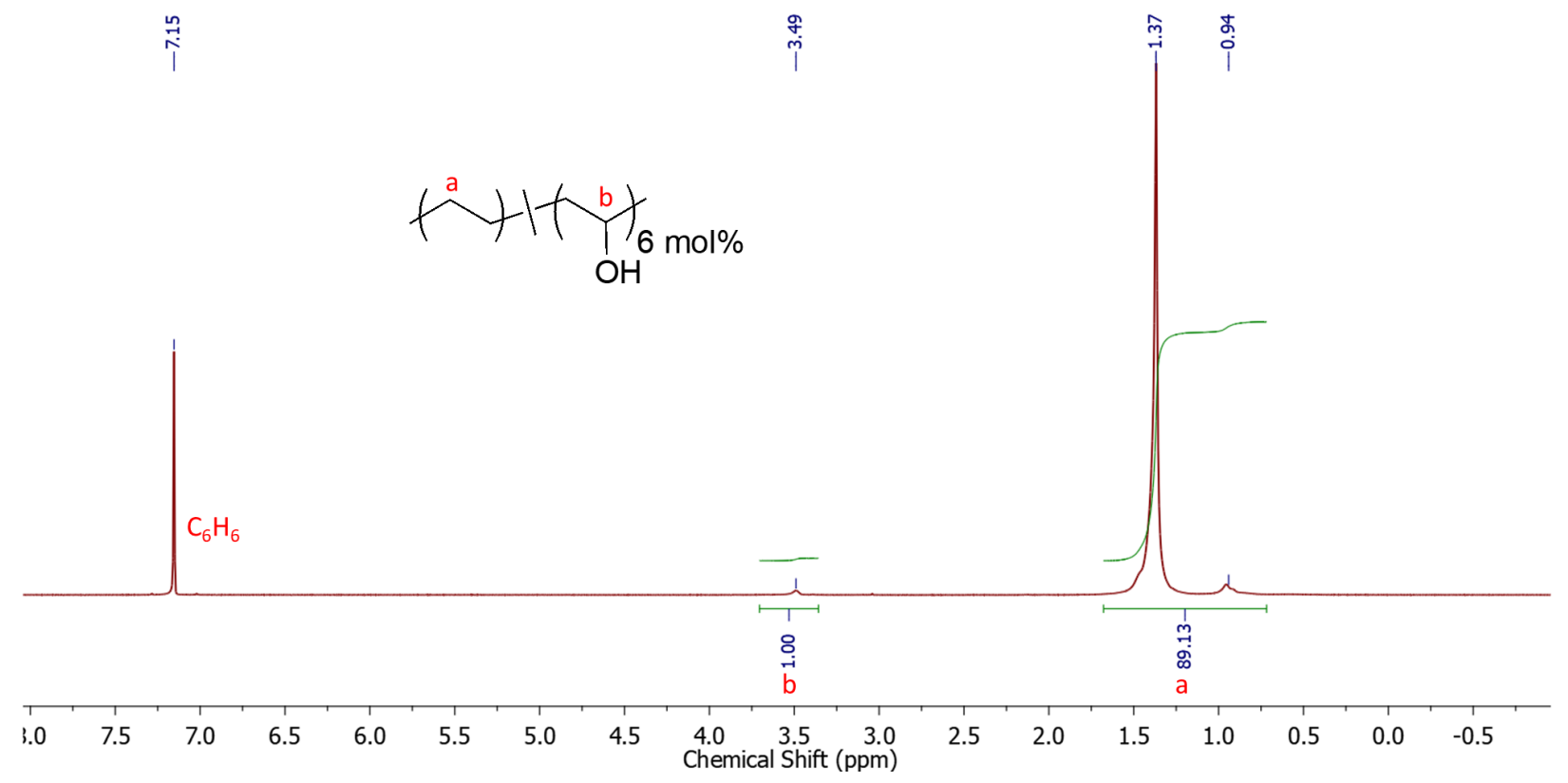

Figure S9. ${ }^{1} \mathrm{H}$ NMR (600 MHz, $\left.\mathrm{C}_{6} \mathrm{D}_{6}, 333 \mathrm{~K}\right)$ spectrum of Poly(ethylene-co-vinyl alcohol).

Scheme S3. Silylation of poly(ethylene-co-vinyl alcohol)

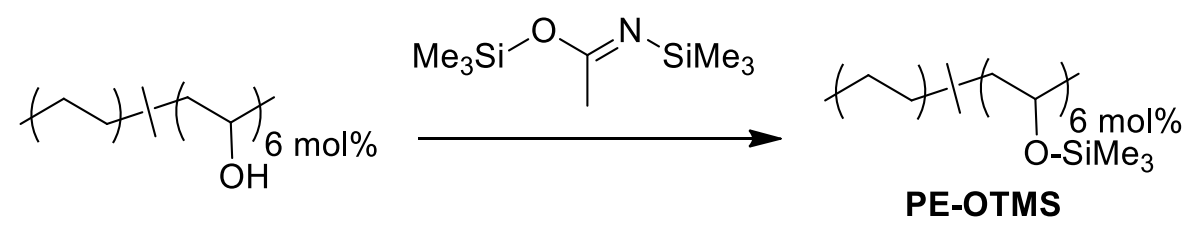

Poly(ethylene-co-vinyl alcohol) $(10.1 \mathrm{~g})$ was dissolved in $200 \mathrm{~mL}$ toluene and heated to $75^{\circ} \mathrm{C}$. To the stirred solution, N,O-bistrimethylsilyl acetamide (BSA, 3 equiv., $14.28 \mathrm{~g}, 17.16 \mathrm{~mL}$ ) was added dropwise via syringe. The reaction mixture stirred overnight, followed by rotary evaporation to remove excess solvent. The light orange polymer was then further dried under high vacuum to remove residual BSA and N-trimethylsilyl acetamide by-product, yielding PE-OTMS as the final product. 


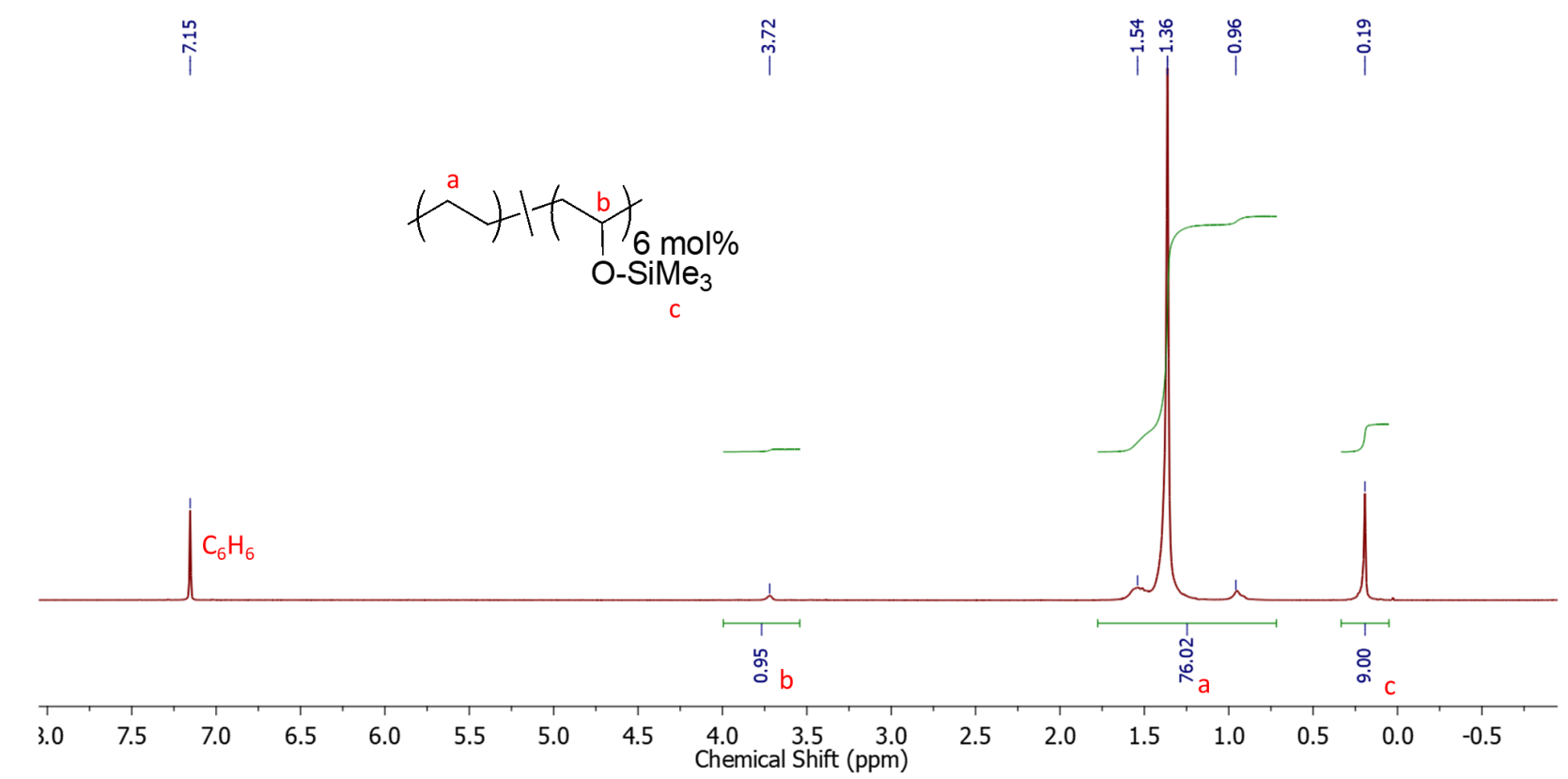

Figure S10. ${ }^{1} \mathrm{H}$ NMR $\left(600 \mathrm{MHz}, \mathrm{C}_{6} \mathrm{D}_{6}, 333 \mathrm{~K}\right)$ spectrum of PE-OTMS.

\section{Synthesis of cross-linker}

Scheme S4. Synthesis of cross-linker.

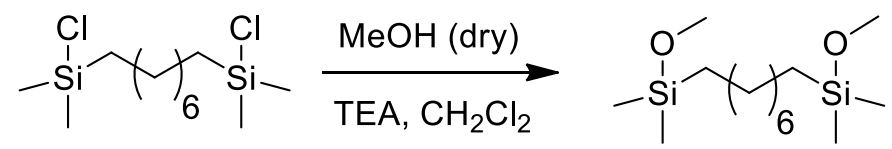

To a flame-dried round bottom flask, anhydrous dichloromethane $(20 \mathrm{~mL})$ and 1,8bis(chlorodimethylsilyl)octane (1 equiv., $15 \mathrm{mmol}, 4.61 \mathrm{~mL}$ ) were added. The flask was sealed with a septum and anhydrous methanol (2.2 equiv., $33 \mathrm{mmol}, 1.33 \mathrm{~mL}$ ) was added, followed by the dropwise addition of TEA (2.2 equiv., $33 \mathrm{mmol}, 4.60 \mathrm{~mL})$. The mixture stirred for 1 hour followed by rotary evaporation. The resulting crude product was washed with diethyl ether $(50 \mathrm{~mL}$ $\mathrm{x} 2$ ) and filtered through a pad of celite to remove ammonium salts. The diethyl ether was removed via rotary evaporation to yield a clear, slightly yellow liquid ( $95 \%$ yield). The identity of the product was determined via ${ }^{1} \mathrm{H}$ NMR. 
1,8-bis(methoxydimethylsilyl)octane ${ }^{1} \mathrm{H}$ NMR $\left(500 \mathrm{MHz}, \mathrm{CDCl}_{3}, 298 \mathrm{~K}\right) \delta 3.42(\mathrm{~s}, 6 \mathrm{H}), 1.31$ (m, 6H), $1.27(\mathrm{~m}, 6 \mathrm{H}), 0.59$ (t, J = $7 \mathrm{~Hz}, 3 \mathrm{H}), 0.09$ (s, $12 \mathrm{H})$.

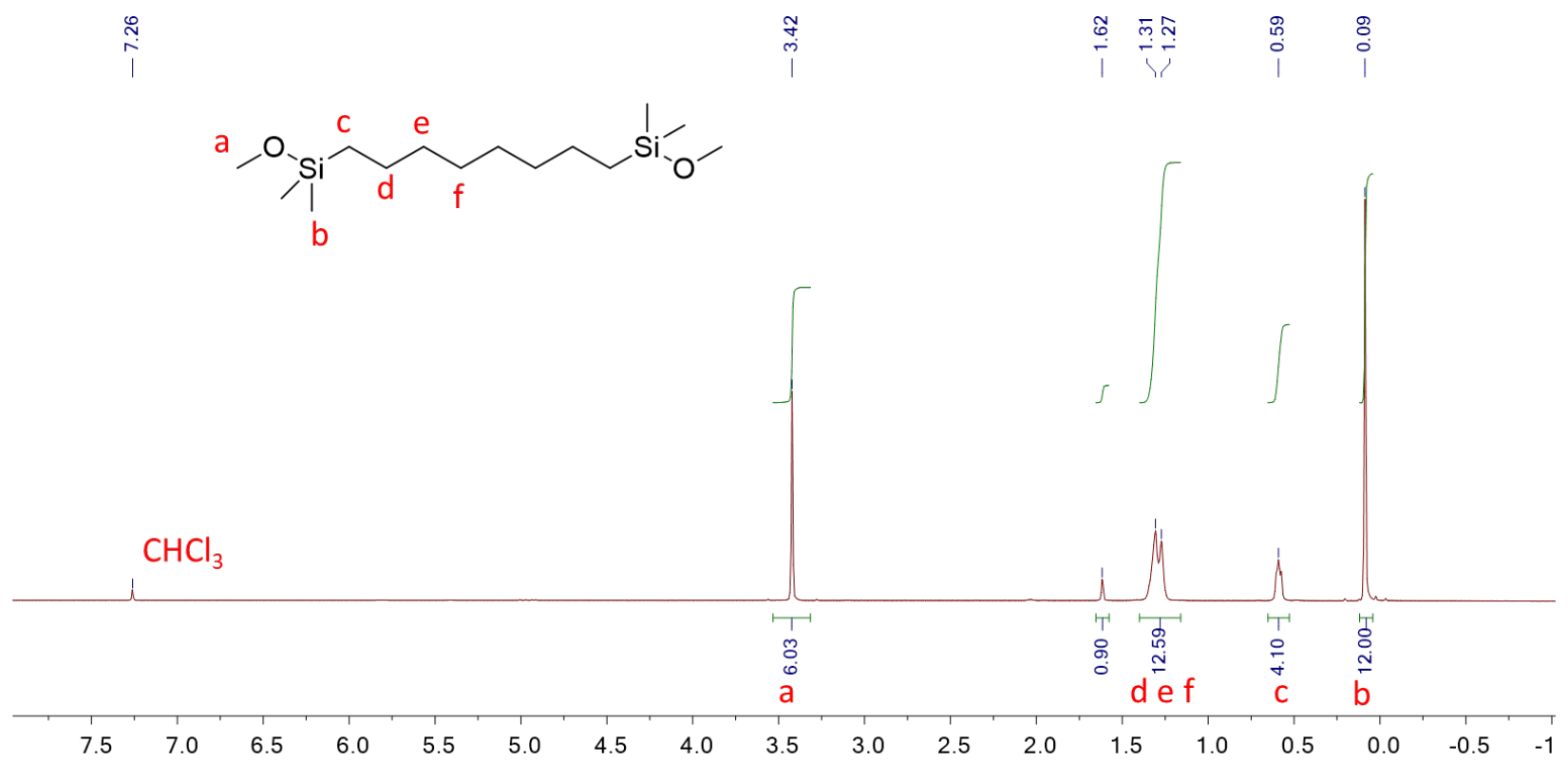

Figure S11. ${ }^{1} \mathrm{H} \mathrm{NMR}\left(500 \mathrm{MHz}, \mathrm{CDCl}_{3}, 298 \mathrm{~K}\right)$ spectrum of 1,8-

\section{bis(methoxydimethylsilyl)octane}




\section{Vitrimer preparation and studies}

Into a flame-dried test tube, $3 \mathrm{~g}$ of PE-OTMS ( 6 mol\% silyl ether) was added, sealed with a septum, and flushed with $\mathrm{N}_{2}$. Anhydrous toluene $(15 \mathrm{~mL})$ was added via syringe and heated to $75{ }^{\circ} \mathrm{C}$ until dissolved. Separately, a stock solution of CSA catalyst was prepared in anhydrous toluene. To the dissolved PE-OTMS, CSA ( $2 \mathrm{~mol} \%$ relative to silyl ether, $0.123 \mathrm{mmol}, 28.5 \mathrm{mg}$ ) was added and stirred to homogenize. The bis-silyl ether cross-linker ( $3 \mathrm{~mol} \%$ relative to silyl ether motif on polymer, $0.184 \mathrm{mmol}, 53.5 \mathrm{mg}$ ) was then added dropwise while vigorously mixing. The temperature was maintained at $75^{\circ} \mathrm{C}$, and the viscosity increased over the course of 10 minutes until the solution became completely gelled. After 30 minutes the gel was removed from the test tube, moved to a PTFE dish, and placed in a $\mathrm{N}_{2}$-flushed vacuum oven heated at $90{ }^{\circ} \mathrm{C}$ to slowly dry for 4 hours. High vacuum was then pulled for 6 hours to remove residual solvent.

The cross-linked network was then cut into small pieces and compression molded with a Specac West 6100+ High Temperature Hot Press. The cut pieces were placed into preheated PTFE molds at $150{ }^{\circ} \mathrm{C}$ and pressurized to 2 tons $(\sim 400 \mathrm{psi})$ for 20 minutes followed by a 30-minute cooldown to room temperature. Samples were then annealed at $150{ }^{\circ} \mathrm{C}$ for 4 hours under gentle pressure prior to testing to ensure full sintering of cut pieces. For reprocessing, the samples were cut into small pieces (approximately $1 \mathrm{~mm}^{3}$ ) with a razor and compression molded as previously described. 


\section{Gel fraction testing}

To test the gel fraction, samples were cut into approximately $30 \mathrm{mg}$ pieces and suspended in excess solvent (dry toluene, $20 \mathrm{~mL}$ ). The pieces were then swollen by heating to $70{ }^{\circ} \mathrm{C}$ for 16 hours. This allowed for un-crosslinked polymer chains to diffuse into the excess solvent, leaving the crosslinked network in the swollen state. The swollen samples were then removed from solvent and dried in a heated vacuum chamber to remove any residual solvent. The weight before and after testing was recorded and the weight fractions are listed in Table 1.

Table S1. Gel fraction data for reprocessed vitrimer samples

\begin{tabular}{|l|l|l|l|}
\hline Reprocessing & Before & After & Insoluble fraction (\%) \\
\hline Processed x1 & $28.9 \mathrm{mg}$ & $18.2 \mathrm{mg}$ & $63.0 \%$ \\
\hline Processed x2 & $31.6 \mathrm{mg}$ & $19.5 \mathrm{mg}$ & $61.7 \%$ \\
\hline Processed x3 & $36.3 \mathrm{mg}$ & $23.2 \mathrm{mg}$ & $64.0 \%$ \\
\hline
\end{tabular}




\section{Thermal characterization of PE-OTMS vitrimer.}

Differential Scanning Calorimetry (DSC) measurements were performed on PE-OTMS linear and vitrimer samples using $\sim 10 \mathrm{mg}$ of material in an aluminum non-hermetic pan (Figure S12 and S13). Samples were scanned against an empty reference pan from $-50{ }^{\circ} \mathrm{C}$ to $150^{\circ} \mathrm{C}$ at a ramp rate of $20^{\circ} \mathrm{C} / \mathrm{min}$. PE-OTMS was found to have a broad melting range from $54{ }^{\circ} \mathrm{C}$ to $104{ }^{\circ} \mathrm{C}$ with the peak endotherm at $93{ }^{\circ} \mathrm{C}$. To determine the degree of crystallinity of PE-OTMS, the area of the endotherm $(94.5 \mathrm{~J} / \mathrm{g})$ is divided by the enthalpy of melting for crystalline LDPE${ }^{1}(293 \mathrm{~J} / \mathrm{g})$ to give a 32.3\% crystalline content. DSC endotherms were calibrated to an indium standard reference.

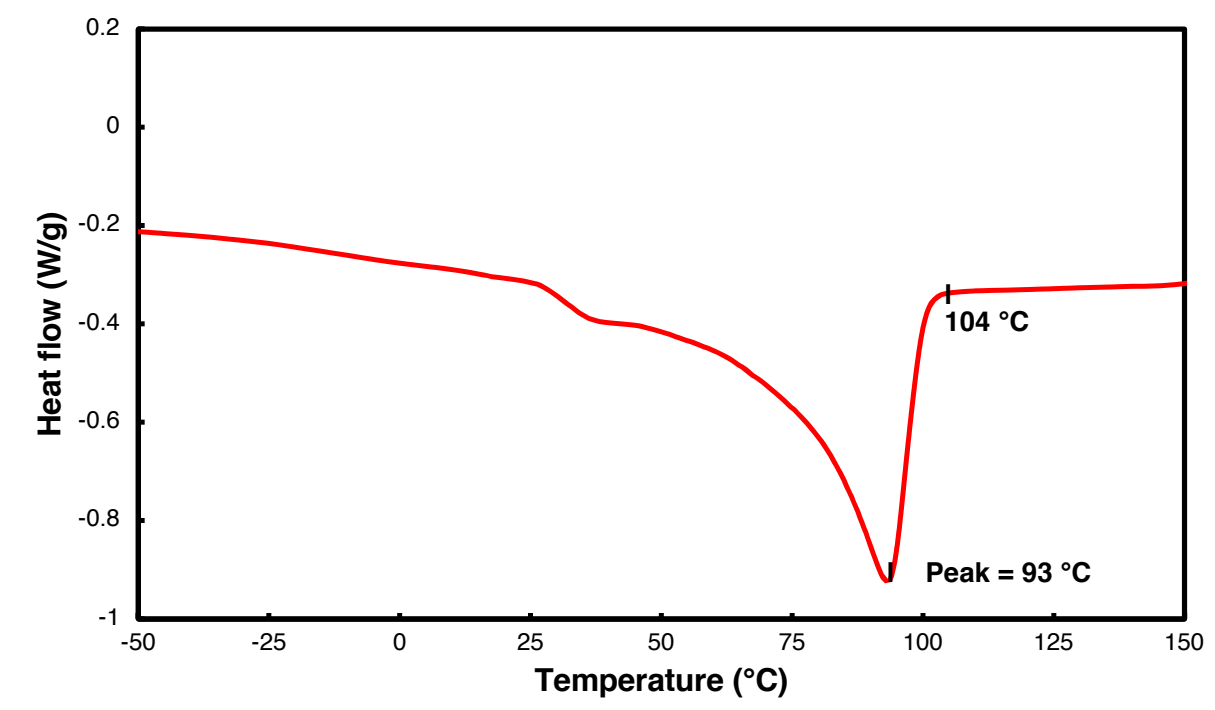

Figure S12. DSC thermogram of PE-OTMS vitrimer from $-50{ }^{\circ} \mathrm{C}$ to $150{ }^{\circ} \mathrm{C}$. 


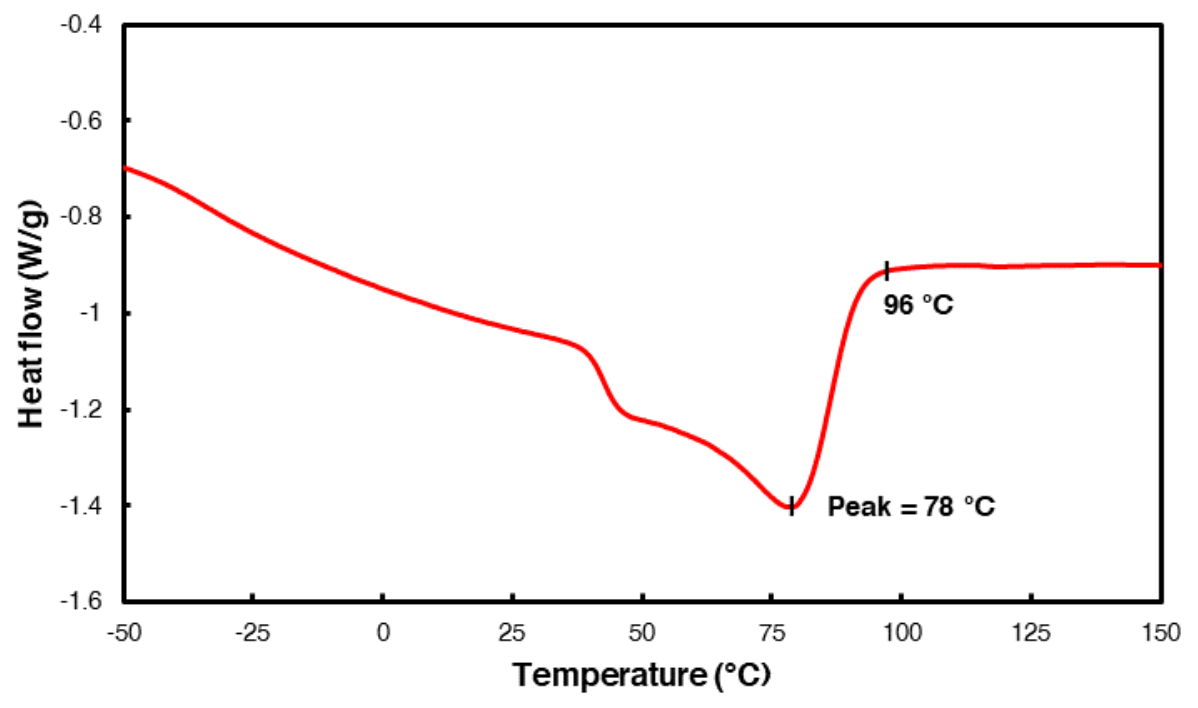

Figure S13. DSC thermogram of linear PE-OTMS from $-50{ }^{\circ} \mathrm{C}$ to $150{ }^{\circ} \mathrm{C}$. 
Thermogravimetric analysis (TGA) was performed to determine polymer stability (Figure S14). The sample was placed in a platinum crucible under constant $\mathrm{N}_{2}$ flow and heated to $850{ }^{\circ} \mathrm{C}$ at 20 ${ }^{\circ} \mathrm{C} /$ min. The sample had lost $\sim 5 \%$ of its original mass at $427{ }^{\circ} \mathrm{C}$ and completely degraded at $\sim 500$ ${ }^{\circ} \mathrm{C}$.

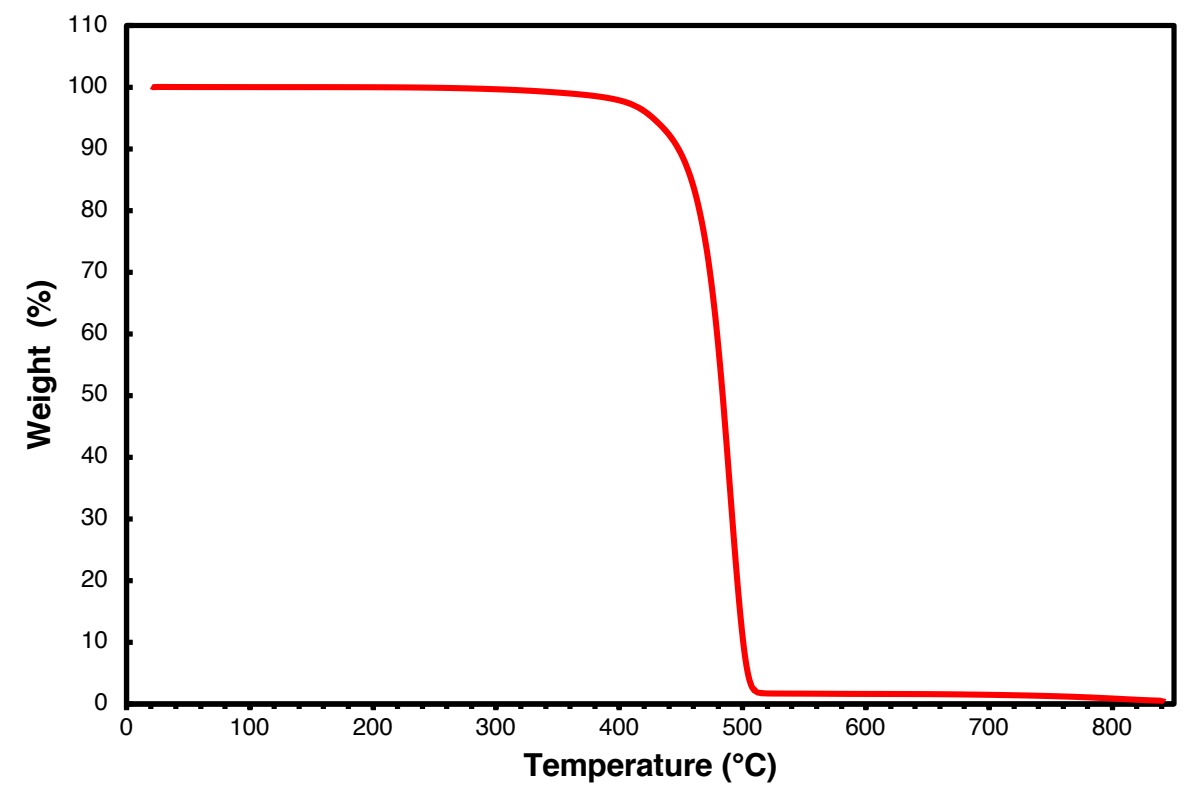

Figure S14. TGA thermogram of PE-OTMS vitrimer 


\section{Tensile testing of PE-OTMS vitrimer}

For tensile testing, the samples were compression molded as previously described and cut into approximately $3 \mathrm{~mm} \times 2 \mathrm{~mm} \times 25 \mathrm{~mm}$ strips. Tensile testing was performed at room temperature at a pull rate of $0.5 \mathrm{~mm} / \mathrm{mm} / \mathrm{min}$. All samples broke cleanly between the clamps.

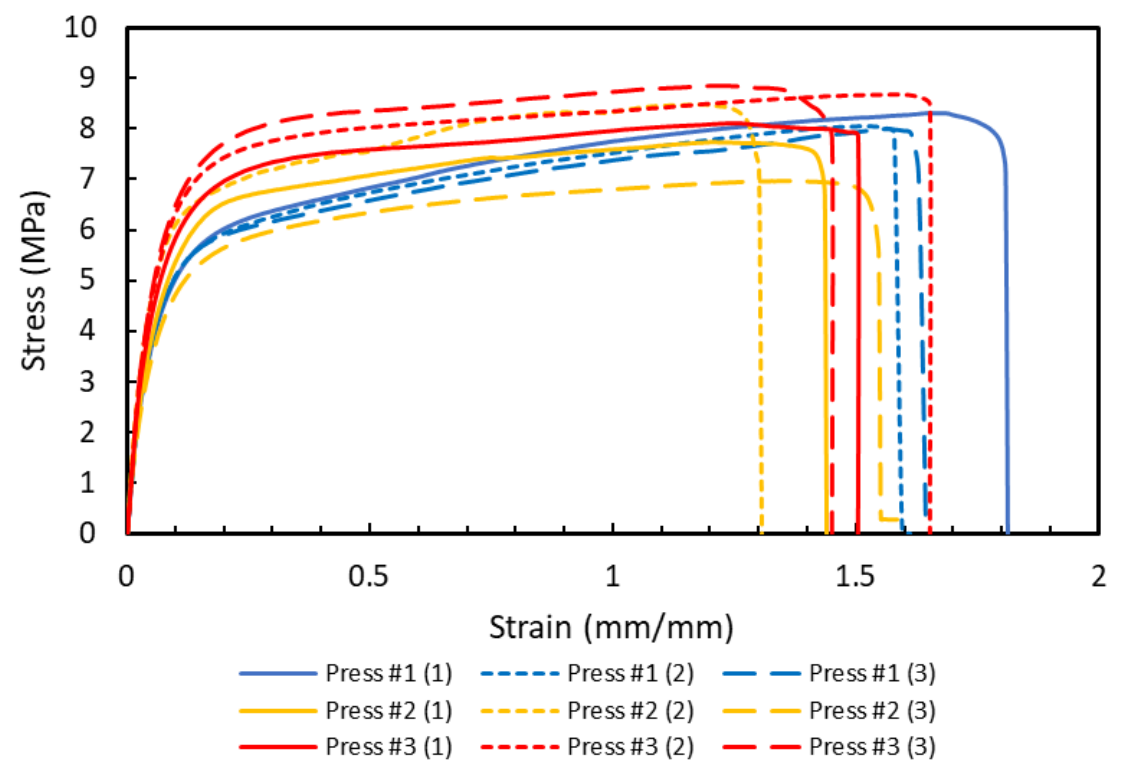

Figure S15. Tensile testing of PE-OTMS vitrimer over three iterations of reprocessing.

Table S2. Mechanical properties of repetitively reprocessed PE-OTMS vitrimer (triplicates).

\begin{tabular}{|l|l|l|l|}
\hline & $\mathrm{x} 1$ & $\mathrm{x} 2$ & $\mathrm{x} 3$ \\
\hline Young's Modulus (MPa) & $101 \pm 19$ & $132 \pm 16$ & $98 \pm 3$ \\
\hline Tensile Strength (MPa) & $8.3 \pm 0.2$ & $7.7 \pm 0.8$ & $8.1 \pm 0.4$ \\
\hline Toughness $\left(\mathrm{MJ} / \mathrm{m}^{3}\right)$ & $13.1 \pm 3.0$ & $10.0 \pm 0.2$ & $11.2 \pm 1.0$ \\
\hline Elongation $(\mathrm{mm} / \mathrm{mm})$ & $1.8 \pm 0.1$ & $1.4 \pm 0.1$ & $1.5 \pm 0.1$ \\
\hline
\end{tabular}




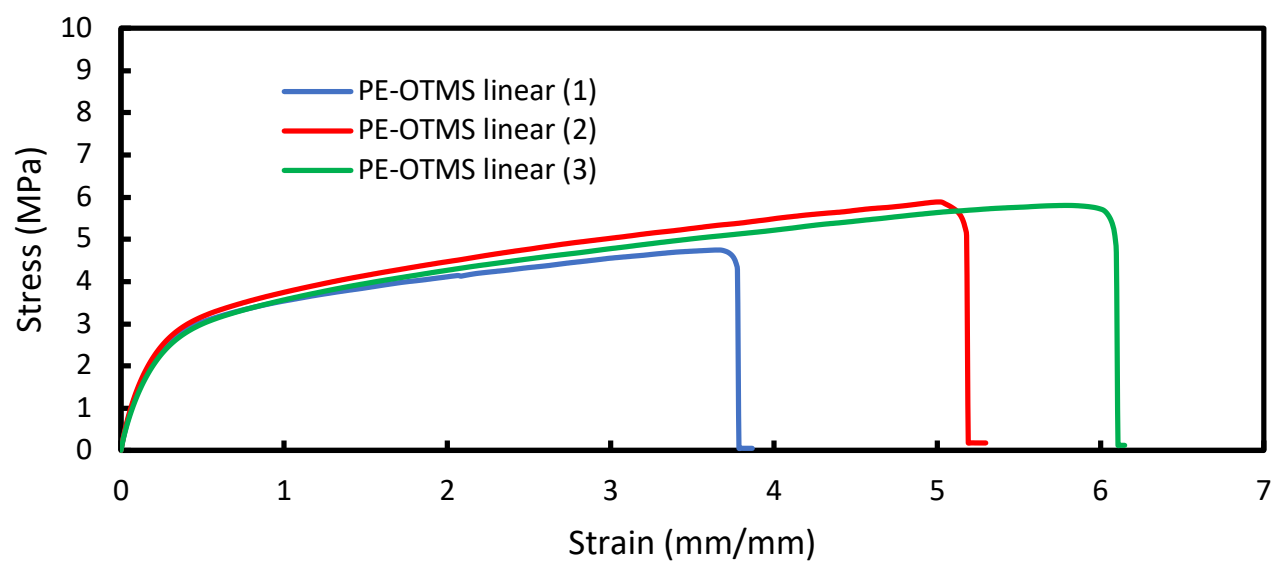

Figure S16. Tensile testing of linear PE-OTMS polymer.

Table S3. Mechanical properties of linear PE-OTMS polymer (triplicates).

\begin{tabular}{|l|c|}
\hline & Linear PE-OTMS \\
\hline Young's Modulus (MPa) & $19.2 \pm 1.13$ \\
\hline Tensile Strength (MPa) & $5.5 \pm 0.6$ \\
\hline Toughness $\left(\mathrm{MJ} / \mathrm{m}^{3}\right)$ & $21.9 \pm 6.8$ \\
\hline Elongation $(\mathrm{mm} / \mathrm{mm})$ & $5.1 \pm 1.2$ \\
\hline
\end{tabular}




\section{Dynamic Mechanical Thermal Analysis (DMTA) testing}

DMTA testing was performed on a DMA Q800 by cutting a sample into thin films approximately $2 \mathrm{~mm} \times 1 \mathrm{~mm} \times 15 \mathrm{~mm}$ and mounting to the clamp in tensile mode. The sample was heated at a constant rate of $3{ }^{\circ} \mathrm{C} / \mathrm{min}$ while subjected to a $15 \mu \mathrm{m}$ amplitude oscillation at $5 \mathrm{~Hz}$. For the linear PE-OTMS (Figure 3A), the sample completely flowed above the $T_{\mathrm{m}}$. However, the PE-OTMS vitrimer showed a rubber plateau and retained elasticity above the $T_{\mathrm{m}}$. The storage modulus plateaued at approximately $0.95 \mathrm{MPa}$, which is indicative of the cross-linked network preventing the flow of material. 


\section{Stress relaxation testing}

Stress relaxation experiments were performed on a DMA Q800 by cutting a sample into thin films approximately $2 \mathrm{~mm} \times 1 \mathrm{~mm} \times 15 \mathrm{~mm}$ and mounting to the clamp in tensile mode (Figure 4). Samples were pulled to $10 \%$ strain and held until the relaxation modulus crossed the relaxation time, $\tau^{*}$, which is defined from the Maxwell model of viscoelastic fluids as the time required for the relaxation modulus to fall to $\mathrm{e}^{-1}(\sim 37 \%)$ from the initial relaxation modulus. The stress relaxation data underwent Arrhenius treatment to yield a straight light with a slope defined by equation (1):

$$
\ln \tau^{*}(T)=9.356 \cdot \frac{1000}{T}-14.445
$$

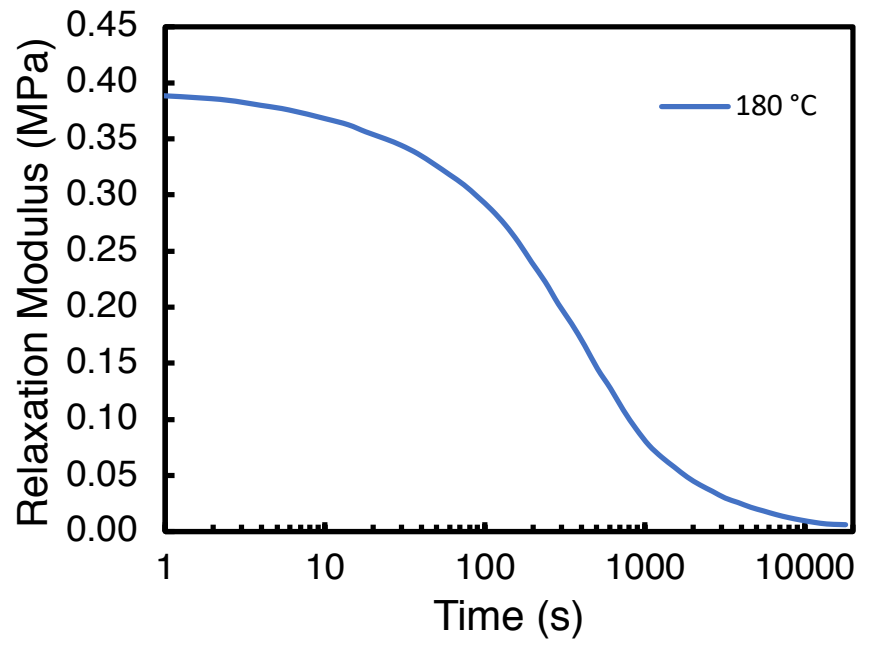

Figure S17. Full stress relaxation curve of the PE-OTMS vitrimer at $180^{\circ} \mathrm{C}$ with $10 \%$ strain. 


\section{Creep testing}

Creep experiments were performed on a DMA Q800 by cutting a sample into thin films approximately $2 \mathrm{~mm} \times 1 \mathrm{~mm} \times 15 \mathrm{~mm}$ and mounting to the clamp in tensile mode. Samples were heated to their respective temperatures and exerted to a constant force of $0.1 \mathrm{MPa}$. After a brief elastic response, the samples begin to creep, following Arrhenius temperature-dependent behavior. After 30 minutes, the force was released and the samples could return to their relaxed state (Figure 3B). The samples at higher temperatures exhibited more creep and consequently did not return to the same position. Due to the melting range, the samples exhibit dramatically different behaviors below and above the $T_{\mathrm{m}}$. While below the $T_{\mathrm{m}}$, the network didn't exhibit as strong of an elastic response - most likely due to the crystalline domains limiting molecular motion. Above the $T_{m}$, the cross-linking stabilizes the material from completely melting.

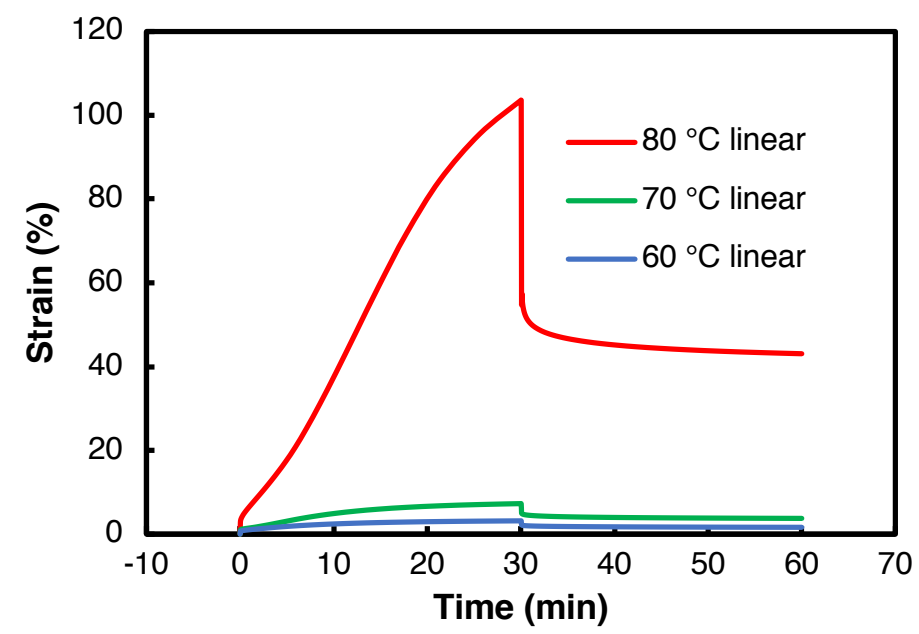

Figure S18. Creep-relaxation testing on linear PE-OTMS polymer. Samples had a $0.1 \mathrm{MPa}$ force applied for 30 minutes followed by relaxation for 30 minutes. 


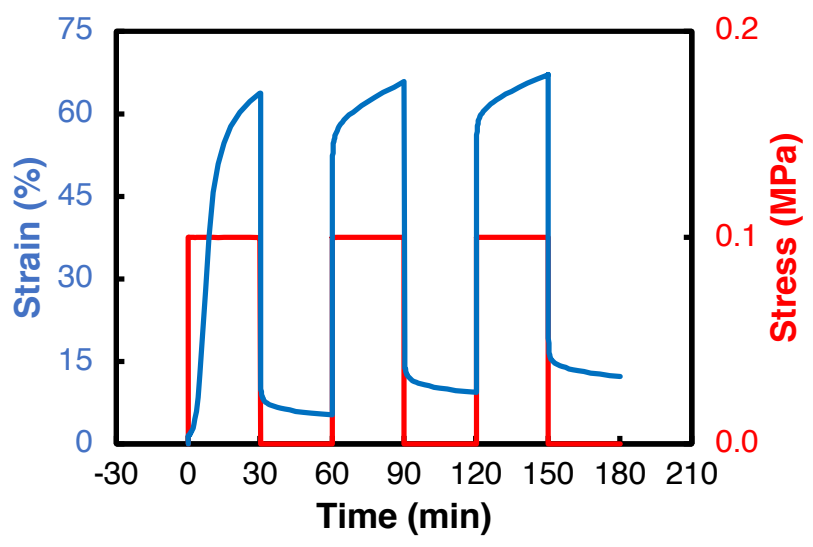

Figure S19. Creep relaxation test at $100{ }^{\circ} \mathrm{C}$ where PE-OTMS vitrimer was cycled three times without removing from the clamp. 


\section{Network dissolution}

To show that cross-linking is not permanent, i.e. no new C-C bonds were formed, a $130 \mathrm{mg}$ piece of a $3 \mathrm{x}$ reprocessed sample was placed in a combination of $90 \%$ toluene and $10 \%$ benzyl alcohol with $10 \mathrm{mg}$ camphor sulfonic acid (CSA). Benzyl alcohol can exchange with the silyl ether crosslinker to un-crosslink the network, leaving only linear polymers behind. Photos were taken before and after heating overnight at $70{ }^{\circ} \mathrm{C}$ (Figure S20). As seen in Fig. S20b, the sample became fully un-crosslinked and soluble.
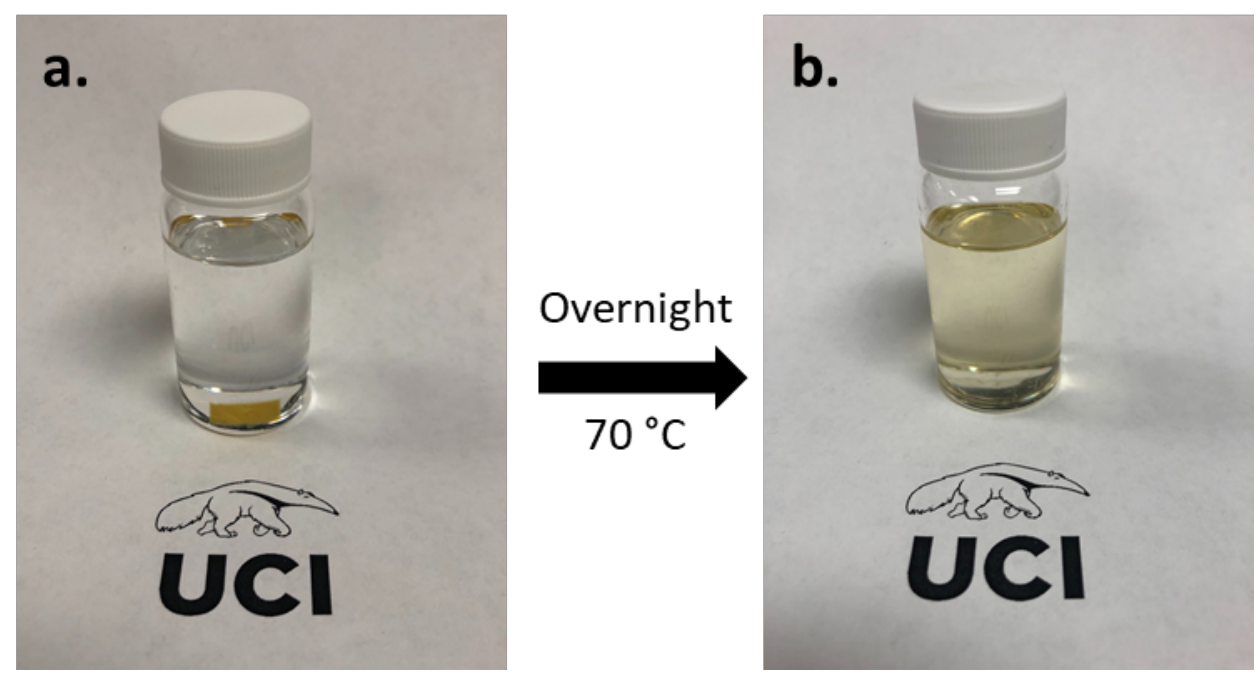

Figure S20. a. $130 \mathrm{mg}$ piece of $3 \mathrm{x}$ reprocessed sample immersed in a solution containing $90 \%$ toluene, $10 \%$ benzyl alcohol, and $10 \mathrm{mg}$ CSA. b. Fully un-crosslinked sample after heating overnight at $70^{\circ} \mathrm{C}$. 


\section{Calculations}

\section{Determination of $T_{v}$}

The topology freezing temperature, $T_{\mathrm{v}}$, is defined as the transition of a material from a viscoelastic solid to a viscoelastic liquid. This transition is generally considered to be when the viscosity reaches $10^{12} \mathrm{~Pa}$. The viscosity can be calculated from DMTA and stress relaxation experiments by using the Maxwell equation: ${ }^{2}$

$$
\eta=G \cdot \tau^{*}=\frac{E^{\prime}}{2(1+v)} \cdot \tau^{*}
$$

Where:

$$
\begin{aligned}
& \mathrm{G}=\text { shear modulus } \\
& \tau^{*}=\text { relaxation time } \\
& \mathrm{E}^{\prime}=\text { storage modulus } \\
& v=\text { Poisson's ratio }
\end{aligned}
$$

By inputting the known Poisson's ratio for LDPE $(0.43)^{3,4}$ into equation (2), it is simplified to:

$$
\eta=0.350 \cdot E^{\prime} \cdot \tau^{*}
$$

Using DMTA analysis of the PE-OTMS vitrimer, the storage modulus at rubber plateau (Figure 3A) was found to be approximately $0.94 \mathrm{MPa}$ for the range of $110-150{ }^{\circ} \mathrm{C}$. The values $\mathrm{E}^{\prime}=0.94$ MPa and $\eta=10^{12} \mathrm{~Pa}$ were inserted into equation (3) to give an extrapolated relaxation time $\tau^{*}=$ $3,039,513 \mathrm{~s}$ for the calculated $T_{\mathrm{v}}$. By plugging the extrapolated $\tau^{*}$ back into equation (1) from stress relaxation, it was found that $T_{\mathrm{v}}=45^{\circ} \mathrm{C}$. 


\section{Determination of $M_{c}$}

Calculation of the molecular weight between cross-links $\left(M_{\mathrm{c}}\right)$ can be performed using the equation: 5

$$
M_{c}=2(1+v) \frac{p R T}{E^{\prime}}
$$

Where:

$$
\begin{aligned}
& v=\text { Poisson's ratio }(0.43) \\
& p=\text { density }\left(0.92 \mathrm{~g} / \mathrm{cm}^{3} \text { or } 920 \mathrm{~kg} / \mathrm{m}^{3}\right)^{6} \\
& \mathrm{R}=\text { universal gas constant }\left(8.314 \mathrm{~m}^{3} \cdot \mathrm{Pa} / \mathrm{K} \cdot \mathrm{mol}\right) \\
& \mathrm{T}=\text { temperature }(413 \mathrm{~K}) \\
& E^{\prime}=\text { storage modulus }\left(0.94 \mathrm{MPa} \text { at } 140{ }^{\circ} \mathrm{C}(413 \mathrm{~K})\right)
\end{aligned}
$$

The $M_{\mathrm{c}}$ value for the PE-OTMS network at $140{ }^{\circ} \mathrm{C}\left(\mathrm{E}^{\prime}=0.94 \mathrm{MPa}\right)$ is found to be $9.61 \mathrm{kDa}$. 


\section{References}

(1) Morawiec, J.; Pawlak, A.; Slouf, M.; Galeski, A.; Piorkowska, E.; Krasnikowa, N. Preparation and Properties of Compatibilized LDPE/Organo-Modified Montmorillonite Nanocomposites. Eur. Polym. J. 2005, 41 (5), 1115-1122.

(2) Capelot, M.; Unterlass, M. M.; Tournilhac, F.; Leibler, L. Catalytic Control of the Vitrimer Glass Transition. ACS Macro Lett. 2012, 1 (7), 789-792.

(3) Sound Velocity in Polyethylene. J. Polym. Sci. 1959, 36 (130), 475-483.

(4) Psomiadou, E.; Arvanitoyannis, I.; Biliaderis, C. G.; Ogawa, H.; Kawasaki, N. Biodegradable Films Made from Low Density Polyethylene (LDPE), Wheat Starch and Soluble Starch for Food Packaging Applications. Part 2. Carbohydr. Polym. 1997, 33 (4), 227-242.

(5) Platzer, N. Encyclopedia of Polymer Science and Engineering, H. F. Mark, N. M. Bikales, C. G. Overberger, and G. Menges, Wiley-Interscience, New York, 1985, 720 Pp. J. Polym. Sci. Part C Polym. Lett. 1986, 24 (7), 359-360.

(6) Zoller, P. The Pressure-Volume-Temperature Properties of Three Well-Characterized Low-Density Polyethylenes. J. Appl. Polym. Sci. 1979, 23 (4), 1051-1056. 